\title{
Effects of ruminal dosing of Holstein cows with Megasphaera elsdenii on milk fat production, ruminal chemistry, and bacterial strain persistence ${ }^{1}$
}

\author{
P. J. Weimer, ${ }^{*} \dagger^{2}$ L. Da Silva Cabral, $\ddagger$ and F. Cacite \\ *USDA-Agricultural Research Service, US Dairy Forage Research Center, Madison, WI 53706 \\ †Department of Bacteriology, University of Wisconsin, Madison 53706 \\ ‡Department of Animal Science, Federal University of Mato Grosso, 78060-900 Cuiabá, Mato Grosso, Brazil
}

\begin{abstract}
Megasphaera elsdenii is a lactate-utilizing bacterium whose ruminal abundance has been shown to be greatly elevated during milk fat depression (MFD). To further examine this association, a total of 23 cannulated multiparous Holstein cows were examined in 3 experiments in which strains of $M$. elsdenii were directly dosed into the rumen $\left(\sim 2 \times 10^{12}\right.$ cells/dose $)$; control cows were dosed with sterile lactate-free culture medium. Cows were fed a total mixed ration $(292 \mathrm{~g}$ of $\mathrm{starch} / \mathrm{kg}$ of dry matter) that contained primarily corn silage, alfalfa silage, finely ground high-moisture corn, supplemental protein, and corn oil (3 g/kg of dry matter). Experiments differed in stage of lactation of the cows (early or late), dosing events (single dose, or 4 doses over a 5 -d period), timing of dose (prefeed or $4 \mathrm{~h}$ postfeed), and M. elsdenii strain (laboratory strain YI9 or 3 strains isolated from cows in the same herd). Dry matter intake and milk yield and composition were measured from 5 to $0 \mathrm{~d}$ before dosing and 1 to $7 \mathrm{~d}$ after first dosing, plus later time points that varied by experiment. Milk yield and composition were not affected by dosing. Megasphaera elsdenii was quantified in the liquid phase of ruminal contents by automated ribosomal intergenic spacer analysis, or by PCR with relative quantification (M. elsdenii 16S rRNA gene copy number as a percentage of total bacterial 16S rRNA gene copies). Neither the $M$. elsdenii-dosed or control cows displayed MFD after dosing, and in almost all cases M. elsdenii populations returned to low baseline levels $(<0.02 \%$ of $16 \mathrm{~S}$ rRNA gene copy number) within $24 \mathrm{~h}$ of dosing. This rapid decline in $M$. elsdenii also occurred in several cows that were dosed with a strain of $M$. elsdenii that had been isolated from that particular cow during a previous bout of MFD. Ruminal $\mathrm{pH}$ and total millimolar
\end{abstract}

Received April 17, 2015.

Accepted July 6, 2015.

${ }^{1}$ Disclaimer: Identification of commercial products is for informational purposes only and does not constitute an endorsement or warranty over other products that may also be suitable.

${ }^{2}$ Corresponding author: Paul.Weimer@ars.usda.gov volatile fatty acids and lactate did not differ between dosed and control cows, although acetate-to-propionate ratio declined in both groups and butyrate increased after dosing with $M$. elsdenii. The results confirm that establishing exogenously added bacterial strains in the rumen is difficult, even for strains previously isolated from the recipient cow. The potential role of M. elsdenii as an agent of MFD remains unclear in the absence of successful establishment of the dosed strains.

Key words: dosing, milk composition, milk fat depression, Megasphaera elsdenii

\section{INTRODUCTION}

Milk fat depression (MFD), defined here for Holstein cows as production of milk having a fat content of $<32$ $\mathrm{g} / \mathrm{kg}$ (Oetzel, 2007), is a serious economic problem in the dairy industry under intensive production conditions. Milk fat depression is thought to arise from suppression of mammary lipogenesis in response to certain trans-FA, particularly trans-10,cis-12 CLA produced by ruminal isomerization and biohydrogenation of unsaturated dietary long-chain FA (Bauman and Griinari, 2003). The specific microbial agents of these biohydrogenation reactions have not been definitively identified. However, early culture-based studies (Latham et al., 1972) noted dramatic increases in the relative abundance of several bacterial species, including Peptostreptococcus (now Megasphaera) elsdenii, in cows upon switching from a high-forage to a high-concentrate diet that was accompanied by a decrease in milk fat percentage from 36 to $16 \mathrm{~g} / \mathrm{kg}$. More recently, several studies using molecular microbial ecological methods (Palmonari et al., 2010; Weimer et al., 2010b; Mohammed et al., 2012) noted that MFD cows contained ruminal bacterial communities that differed in composition from those of non-MFD cows, with a major difference being the relative population size of $M$. elsdenii. Specifically, the 16S rRNA gene copy number of $M$. elsdenii (a proxy measurement for relative population size) comprised up to $4 \%$ of the $16 \mathrm{~S}$ rRNA gene copy number of the total bacterial community in MFD cows, but did not 
exceed $0.02 \%$ in cows before the onset of MFD, or in cows that did not exhibit MFD when fed MFD-eliciting diets rich in some combination of rapidly fermentable carbohydrate, corn oil, and monensin (Weimer et al., 2010b). Although microbial contributions to MFD may ultimately be due to numerous different species, there are demonstrated, robust associations between $M$. elsdenii abundance and MFD. However, no causative role for this bacterium in the establishment or maintenance of MFD has been demonstrated.

Megasphaera elsdenii has a unique physiology and ecology. It can ferment glucose using a reverse $\beta$-oxidation pathway to produce butyric $\left(\mathrm{C}_{4}\right)$ and caproic $\left(\mathrm{C}_{6}\right)$ acids from an acetic acid $\left(\mathrm{C}_{2}\right)$ intermediate. In addition, it can ferment lactic acid to acetic and propionic $\left(\mathrm{C}_{3}\right)$ acids, with conversion of these acids to valeric $\left(\mathrm{C}_{5}\right)$ acid also via reverse $\beta$-oxidation (Hino et al., 1994). As one of the few ruminal bacterial species known to ferment lactate, $M$. elsdenii is considered to be beneficial in attenuating lactic acidosis by converting the more acidic lactate $\left(\mathrm{p} K_{\mathrm{a}} \sim 3.8\right)$ to the less acidic VFA $\left(\mathrm{p} K_{\mathrm{a}} \sim 4.8\right.$; Russell and Hino, 1985; Krause and Oetzel, 2006), and by decreasing the number of acidic carboxyl groups (e.g., by converting 1 propionate +1 acetate $\rightarrow 1$ valerate). In fact, preserved cultures of $M$. elsdenii have been patented as a probiotic for control of lactic acidosis (Leedle et al., 1990; Horn et al., 2009). Thus, M. elsdenii may be unique in a possible dual role in both improving animal performance (by limiting ruminal acidosis) and reducing animal performance (via MFD).

One factor that complicates the assignment of $M$. elsdenii as an agent of MFD is that its biohydrogenation capacity - specifically its ability to produce trans10, cis-12-CLA - is disputed and may be strain-specific (Kim et al., 2002; Maia et al., 2007). Several reports have described experiments in which $M$. elsdenii was deliberately dosed into the rumen to gauge its effects on ruminal chemistry ( $\mathrm{pH}$ and organic acid concentrations) and animal performance. These studies have yielded contradictory results (Klieve et al., 2003; Hagg et al., 2010; Meissner et al., 2010; Aikman et al., 2011; Henning et al., 2011); in general, treatment effects on both ruminal $\mathrm{pH}$ and milk production and composition have been minimal or absent. But in only one of these studies (Klieve et al., 2003) were any population assessments made to determine whether or not the dosed strain persisted in the rumen, which is a key consideration given the well-known difficulty of establishing exogenously added strains in a well-adapted animal (Weimer, 1998).

Unlike previous studies aimed at examining M. elsdenii as a probiotic for attenuating ruminal acidosis, the purpose of our study was to examine the effects of directly dosing $M$. elsdenii into the rumen on milk production and composition, ruminal chemistry, and relative population size of $M$. elsdenii in the rumen. Our intent was to determine if dosing could result in establishment of robust populations of $M$. elsdenii over a narrow time span, with a concomitant demonstration of effects on milk fat yield or fat content of the milk. To provide a wide range of challenges to the cows we conducted 3 experiments in which we varied the frequency, amount, and timing of the dosing. Moreover, we varied the specific strain of $M$. elsdenii to include a laboratory strain and several fresh isolates obtained from cows of varying MFD status. In several cases, we inoculated particular M. elsdenii strains back into the same cows from which they had originally been isolated.

\section{MATERIALS AND METHODS}

\section{Bacterial Strains}

A culture of $M$. elsdenii strain YI-9 was generously provided by M. D. Flythe (USDA-Agricultural Research Service, Lexington, KY). Other strains of this species were isolated from the rumens of cows in the same herd used in our study, using ruminal fluid collected just before daily feeding on the same day that milk samples were collected for compositional analysis to determine the cows' milk fat status. Enrichment cultures were set up within $2 \mathrm{~h}$ of ruminal fluid collection, but only enrichments from cows shown to be fat-depressed were maintained. The enrichment culture medium was lactate/trypticase/yeast extract (LTY medium; described by Weimer and Moen, 2013) to which we added additional agents to select against competitors or their symbionts, which may have been able to use fermentation-produced $\mathrm{H}_{2}: 1 \mathrm{mM} \mathrm{NaMoO}_{4}$ plus $0.12 \mathrm{mM}$ 1,8-dihydroxyanthraquinone (to inhibit sulfate-reducers); and $0.01 \mathrm{mM}$ 2-bromoethanesulfonic acid plus $0.02 \mathrm{~mL}$ of chloroform/L (to inhibit methanogens). In addition, monensin (to which $M$. elsdenii is particularly resistant but the lactate-utilizer Selenomonas ruminantium var. lactilytica is relatively sensitive) was added at $0.5 \mu M$. Ruminal fluid (freshly squeezed through 4 layers of cheesecloth) was added as an inoculum ( $0.1 \mathrm{~mL}$ per $10 \mathrm{~mL}$ of medium), and tubes were incubated at $39^{\circ} \mathrm{C}$. After 1 to $3 \mathrm{~d}$, cultures that displayed substantial turbidity but little or no gas production were examined by phase-contrast microscopy. Cultures containing cells that displayed distinctive $M$. elsdenii morphology (phase-neutral, moderately large cocci in pairs or short chains) were successively transferred to fresh enrichment medium until the putative $M$. elsdenii morphotypes dominated the culture, upon which cultures were streaked to the above medium solidified in 
agar plates in an anaerobic glove bag (gas phase $2 \%$ $\mathrm{H}_{2}, 40 \% \mathrm{~N}_{2}$, remainder $\mathrm{CO}_{2}$ ). After incubation at $39^{\circ} \mathrm{C}$ for 2 to $5 \mathrm{~d}$, isolated colonies were picked into LTY medium lacking the selective agents. Culture identity was verified by microscopic confirmation of morphology, by production of propionic and valeric acid from lactic acid (determined by HPLC), and by quantitative realtime PCR (qPCR) using M. elsdenii-specific primers (Stevenson and Weimer, 2007). The 3 isolated strains (designated with a strain number corresponding to the herd ID number of the source cow) were obtained from cows whose fat test at the time of ruminal sampling for enrichment cultures were 18,21, and $33 \mathrm{~g}$ of fat/ $\mathrm{kg}$ of milk, respectively (sampling date Nov. 25, 2013, see Figure 1). To retain (to the extent possible) their physiological traits at the time of isolation, fresh isolates were stored in $50 \%$ (vol/vol) glycerol under $\mathrm{CO}_{2}$ at $-80^{\circ} \mathrm{C}$ before their revival for dosing experiments.

Inocula for ruminal dosing experiments were prepared by inoculating $100 \mathrm{~mL}$ of pure cultures (grown $\sim 24 \mathrm{~h}$ in serum vials on LTY) into glass carboys that contained 9 to $12 \mathrm{~L}$ of prewarmed, filter-sterilized LTY medium (initial lactate content $=100 \mathrm{mM}$ ), followed by incubation for $\sim 24 \mathrm{~h}$ at $39^{\circ} \mathrm{C}$. Cell densities in the carboys were determined by diluting culture samples at the time of ruminal dosing into an equal volume of glycerol, followed by direct counting of cells in a Petroff-Hauser chamber (Arthur H. Thomas, Philadelphia, PA) examined under phase contrast using a Zeiss Axioskop microscope (Carl Zeiss Microscopy GmbH, Jena, Germany).

\section{Dosing Experiments}

All animal work was conducted at the USDAAgricultural Research Service Dairy Forage Research Center farm near Prairie du Sac, Wisconsin, in accordance with National Institutes of Health and USDA guidelines, under protocol A01427 approved by the University of Wisconsin College of Agricultural and Life Sciences Animal Care and Use Committee. To provide a set of different conditions for potential establishment of the dosed M. elsdenii strains, 3 separate dosing experiments were conducted, each using multiparous, ruminally cannulated Holstein cows.

Diets were formulated to meet the nutritional requirements of lactating dairy cows (NRC, 2001). In particular, the diets (initially fed 10 to $14 \mathrm{~d}$ before strain inoculation) were designed to provide ingredient compositions near those known to put some cows at risk

\section{Cow Lact DIM MY $(\mathrm{kg} / \mathrm{d})$ Fat $(\mathrm{g} / \mathrm{kg})$ Fat $(\mathrm{kg} / \mathrm{d})$}

\begin{tabular}{|c|c|c|c|c|c|c|c|}
\hline M. elsdenii 4251 & dosed & 4251 & 2 & 280 & 38.6 & 33 & 1.28 \\
\hline Fat test $11 / 25 / 13$ & 2/24/14 & 4073 & 2 & 262 & 42.7 & 33 & 1.41 \\
\hline Cow $4251=18 \mathrm{~g} / \mathrm{kg}$ & & 4288 & 3 & 289 & 30.4 & 54 & 1.64 \\
\hline M. elsdenii 4257 & dosed & 4257 & 2 & 264 & 30.0 & 47 & 1.41 \\
\hline Fat test $11 / 25 / 13$ & $2 / 24 / 14$ & 3857 & 3 & 258 & 39.5 & 32 & 1.26 \\
\hline Cow $4257=24 \mathrm{~g} / \mathrm{kg}$ & into & 4261 & 2 & 289 & 25.4 & 43 & 1.09 \\
\hline M. elsdenii 4296 & dosed & 4296 & 2 & 258 & 53.6 & 32 & 1.26 \\
\hline Fat test $11 / 25 / 13$ & 2/24/14 & 3833 & 3 & 285 & 47.2 & 33 & 1.28 \\
\hline Cow $4296=33 \mathrm{~g} / \mathrm{kg}$ & Into & 4297 & 2 & 275 & 30.4 & 43 & 1.31 \\
\hline Sterile medium & $\begin{array}{c}\text { dosed } \\
2 / 24 / 14\end{array}$ & 3874 & 3 & 259 & 38.1 & 46 & 1.75 \\
\hline without lactate & $\begin{array}{l}2<2474 \\
\text { into }\end{array}$ & 4004 & 2 & 217 & 50.4 & 32 & 1.92 \\
\hline
\end{tabular}

Figure 1. Schematic of experiment 2: The 3 Megasphaera elsdenii strains were isolated from ruminal samples collected the same day as the milk samples collected for the fat test, at which time cows 4251 and 4257 displayed milk fat depression, and cow 4296 was borderline. Isolates from the enrichment culture were archived at $-80^{\circ} \mathrm{C}$ for the dosing experiment. The lactation information for each dosed cow [lactation number (Lact), DIM, milk yield (MY), fat content $(\mathrm{g} / \mathrm{kg})$, and fat yield $(\mathrm{kg} / \mathrm{d})]$ is indicated $5 \mathrm{~d}$ before dosing, at which time none of the cows displayed milk fat depression. 
for MFD, but without inducing MFD in the absence of inoculation. As the experiments were conducted over the course of 14 mo, some differences existed across trials with respect to dietary ingredients used to achieve a similar nutrient composition (Table 1). Individual experiments differed with regard to the M. elsdenii strain used, individual recipient cows, amount of culture dosed, and dosing time within the feeding cycle (summarized in Table 2). Dosing was accomplished by direct addition of 2.8 to $3.0 \mathrm{~L}$ of culture through the ruminal cannula of each cow. Control cows were dosed with sterile LTY medium without lactate to simulate the salts content of the culture medium. These 2 groups will subsequently be referred to as dosed cows and control cows, respectively. Prior to each individual experiment, cows were grouped to achieve similar parity, DIM, and milk yield, and at the start of each experiment none of the cows had milk fat content of under $32 \mathrm{~g} / \mathrm{kg}$ at their most recent fat test.

\section{Sample Collection and Analysis}

Depending on the experiment, milk samples were collected at each milking $(2 \times$ or $3 \times$ daily) for a minimum of $5 \mathrm{~d}$ before first dosing through $7 \mathrm{~d}$ after first dosing, and at additional days over the following $3 \mathrm{wk}$ (see Table 2). Milk composition of these samples was predicted by near-infrared spectroscopy (NIRS; AgSource, Verona, WI). Daily concentrations of milk components were calculated from the daily yields of milk and each component [e.g., grams of fat per kilograms of milk $=1,000 \times$ (daily kilograms of fat/daily kilograms of milk). Dry matter intake was measured daily through the entire experiment for each cow ( $\mathrm{d}-5$ to $30,-10$ to 21 , and -5 to 7 for experiments 1,2 , and 3 , respectively).

Ruminal $\mathrm{pH}$ was determined by direct insertion into the rumen, through the ruminal cannula opening, of a $\mathrm{pH}$ probe attached to a portable digital $\mathrm{pH}$ meter (model 340i, WTW, Weinheim, Germany) at the time of sampling ruminal contents. The meter was calibrated at $\mathrm{pH} 4.01$ and 7.00 just before use. Ruminal samples were collected for analysis of microbial fermentation products and for quantification of $M$. elsdenii, which in several prior studies were found to be detectable only in the liquid phase of ruminal contents [though it has been reported to be at very low abundance in the epimural contents of beef cattle (Petri et al., 2013); abundance in the epimural community of dairy cattle rumens has not been reported]. Collections were made through the ruminal cannula from the medio-ventral region of the rumen. The time of sample collection relative to feeding depended on the experiment (Table 2). Samples were squeezed cow-side through 4 layers of cheesecloth, into sterile 50-mL plastic Corning centrifuge tubes (Corning Inc., Corning, NY). Tubes were immediately chilled on ice, transported to the laboratory, and, after removal of a subsample for organic acid analysis, were frozen at $-80^{\circ} \mathrm{C}$. Organic acids (individual $\mathrm{C}_{2}-\mathrm{C}_{5} \mathrm{VFA}$, lactate, and succinate) were analyzed by HPLC (Weimer et al., 1991).

Table 1. Diets used in dosing experiments

\begin{tabular}{|c|c|c|c|}
\hline Item $(\mathrm{g} / \mathrm{kg}$ of $\mathrm{DM})$ & Experiment 1 & Experiment 2 & Experiment 3 \\
\hline \multicolumn{4}{|l|}{ Ingredient } \\
\hline Brown midrib corn silage & 345 & 338 & - \\
\hline Conventional corn silage & - & - & 280 \\
\hline Alfalfa haylage & 123 & 244 & 326 \\
\hline High-moisture corn, finely ground & 238 & 240 & 221 \\
\hline Canola meal & 73 & 110 & 67 \\
\hline Roasted soybeans & 75 & - & 36 \\
\hline Distillers grains & 121 & 40 & 42 \\
\hline Corn oil $^{1}$ & - & 3 & 3 \\
\hline Vitamin/mineral mix with Rumensin ${ }^{2}$ & 25 & 25 & 25 \\
\hline \multicolumn{4}{|l|}{ Component } \\
\hline $\mathrm{aNDF}^{3}$ & 292 & 277 & 280 \\
\hline $\mathrm{NFC}^{4}$ & 438 & 458 & 433 \\
\hline $\mathrm{CP}$ & 167 & 165 & 165 \\
\hline Fat & 50 & 44 & 45 \\
\hline Ash & 53 & 56 & 78 \\
\hline
\end{tabular}

${ }^{1}$ Butcher Boy (Columbus Vegetable Oils, Des Plaines, IL).

${ }^{2}$ Contained (per $\mathrm{kg}$ of mix): $168.4 \mathrm{~g}$ of Ca, $158 \mathrm{~g}$ of Na, $47.8 \mathrm{~g}$ of $\mathrm{Mg}, 5.8 \mathrm{~g}$ of $\mathrm{K}, 71.1 \mathrm{~g}$ of Cl, $10.6 \mathrm{~g}$ of S, $2.78 \mathrm{~g}$ of Mn, $3.0 \mathrm{~g}$ of $\mathrm{Zn}, 0.778 \mathrm{~g}$ of Fe, $0.55 \mathrm{~g}$ of $\mathrm{Cu}, 0.045 \mathrm{~g}$ of Co, $0.064 \mathrm{~g}$ of I, $0.016 \mathrm{~g}$ of Se, 291,000 IU of vitamin A, 58,400 IU of vitamin D, 1,360 IU of vitamin E, $0.48 \mathrm{~g}$ of Rumensin (Elanco Animal Health, Greenfield, IN). ${ }^{3} \mathrm{NDF}$ assayed with $\alpha$-amylase and Na sulfite. Fraction of aNDF derived from forage was $0.503,0.574$, and 0.564 for experiments 1,2 , and 3 , respectively.

${ }^{4}$ Starch content of diet was 310,287 , and $280 \mathrm{~g} / \mathrm{kg}$ of DM for experiments 1,2 , and 3 , respectively. 
At the conclusion of each trial, frozen ruminal fluid samples were thawed and DNA was isolated from 25 $\mathrm{mL}$ of sample using the method of Stevenson and Weimer (2007). The isolation procedure is essentially identical to the PCSA (bead beating in the presence of phenol-chloroform) procedure described in Table 1 of Henderson et al. (2013) that gave the highest yield and, likely, most representative community composition of 13 tested methods. The isolated DNA was used in 2 culture-independent methods for quantification of $M$. elsdenii. In experiment 1, automated ribosomal intergenic spacer analysis (ARISA) was used to quantify the 246-bp amplicon characteristic of M. elsdenii (Palmonari et al., 2010) using DNA from M. elsdenii YI9 as a standard. In experiments 2 and 3 , relative quantification qPCR analysis was conducted as described previously (Stevenson and Weimer, 2007) using DNA isolated from M. elsdenii T81 as a standard. For qPCR analysis, M. elsdenii was reported as a relative population size (RPS), defined here as the 16S rRNA gene copy number of $M$. elsdenii as a percentage of the $16 \mathrm{~S}$ rRNA gene copy number of the entire domain bacteria.

\section{Statistical Analysis}

All statistical analyses were conducted in SAS version 9.4 (SAS Institute Inc., Cary, NC) using PROC MIXED. Repeated measures were used for analysis to incorporate individual sampling days. The covariance structure of the mixed model for each output variable was selected based on the smallest Akaike information criterion fit statistic. For each experiment, main effects of treatment (dosed strain or control), period (pre- vs. postdosing), experimental day within period, and treatment by period and treatment by day within period interactions were determined for the output variables for production (daily yields of milk, fat, protein, and lactose, as well concentrations of these components in grams per kilogram of milk, and MUN), ruminal chemistry $(\mathrm{pH}$, millimolar lactate, total millimolar VFA, molar fraction of individual VFA, and acetate-to-propionate ratio), and RPS of M. elsdenii. Least squares means for each output variable were compared using Tukey's test, with significance declared at $P<0.05$ and a tendency declared at $0.05<P<0.10$. In addition, output variables within individual cows across treatment periods (described within individual experiments below) were compared using a $t$-test.

\section{RESULTS}

\section{Experiment 1}

In the first experiment, late-lactation cows that displayed a normal fat test $1 \mathrm{wk}$ before the start of the experiment were subjected to a single dose of laboratory strain M. elsdenii YI-9 just before feeding. Within treatment group, milk composition did not differ be-

Table 2. Summary of conditions for dosing experiments

\begin{tabular}{|c|c|c|c|}
\hline Condition & Experiment 1 & Experiment 2 & Experiment 3 \\
\hline Number of cows & 3 , plus 3 controls & 3 per strain $^{1}$, plus 2 controls & $4^{1}$, plus 3 controls \\
\hline Parity, mean (range) & $2.5(2-4)$ & $2.27(2-3)$ & $2.88(2-3)$ \\
\hline BW $(\mathrm{kg})$, mean (range) & $765(709-840)$ & $729(627-861)$ & $734(639-855)$ \\
\hline Dosing & Single & 4 doses over $5 \mathrm{~d}$ & Single \\
\hline Dosing time relative to feeding & Prefeed & Prefeed & $4 \mathrm{~h}$ postfeed ${ }^{2}$ \\
\hline $\begin{array}{l}\text { Ruminal sampling, d relative to } \\
\text { dosing date (or, for experiment } 2 \text {, } \\
\text { first dosing date) })^{3}\end{array}$ & $\begin{array}{l}-4,-1,0,1,2,3,7,10,14 \\
21,28\end{array}$ & $\begin{array}{l}-10,-4,-3,0,1,2,3,4,7,9,11 \\
14,21\end{array}$ & $-5,-3,0,1,2,3,7$ \\
\hline $\begin{array}{l}\text { Milk sampling, d relative to dosing } \\
\text { date (or, for experiment } 2 \text {, first } \\
\text { dosing date) }\end{array}$ & $\begin{array}{l}-5 \text { to } 9 \text {, and } 24 \text { to } 30(2 \times \\
\text { daily) }\end{array}$ & $\begin{array}{l}-6 \text { to } 7,9,11,14,18,21(3 \times \\
\text { daily) }\end{array}$ & $\begin{array}{l}-5,-3,0,1 \text { to } 7(3 \times \\
\text { daily })\end{array}$ \\
\hline
\end{tabular}

${ }^{1}$ One of the cows dosed for each strain was the cow from which the strain was isolated. Control cows were dosed with sterile lactate-free medium.

${ }^{2}$ Approximately $8 \mathrm{~L}$ of ruminal contents removed before dosing (see text).

${ }^{3}$ Negative numbers refer to days before dosing (or, for experiment 2, before first dosing). On dosing days in italics, ruminal samples were collected immediately before dosing, and again $\sim 1 \mathrm{~h}$ after dosing to yield predose and postdose samples, respectively. On all other days, ruminal samples were collected to correspond with the original timing of the dose (prefeed for experiments 1 and 2 , and $4 \mathrm{~h}$ postfeed for experiment 3 ). Where ranges are indicated (e.g., -5 to 9 ), milk samples were collected at every milking (2 or 3 times daily, depending on experiment) within the range of days.

${ }^{4} \mathrm{ARISA}=$ automated ribosomal intergenic spacer analysis, based on characteristic 246-bp intergenic spacer length; qPCR $=$ quantitative realtime PCR using M. elsdenii-specific primers. 
tween the 2 postdose periods (d 1 to 7 vs. d 14 to 21; Table 3). Dry matter intake and yield of milk and components (fat, protein, and lactose) all declined in the postdosing periods for both the dosed and control cows (Table 3), as expected for these late-lactation cows. Milk production, milk fat content, and fat yield did not differ between the dosed and control group. Significant dose by period interactions were noted for DMI, fat yield, and percent protein. A separate analysis of milk production and composition during the first $3 \mathrm{~d}$ of dosing revealed no difference in milk composition between the 7 -d predosing period and the first $3 \mathrm{~d}$ postdosing (data not shown). Overall, milk from the dosed cows had lower protein content than did milk from the control cows, but within each group no difference in protein content was noted between the predose and postdose periods. Although no effect of dosing on milk fat production was apparent, comparison of milk yield and concentration across treatment periods within individual cows (Figure 2) revealed that one of the dosed cows (cow 4250) displayed a slightly reduced fat concentration during the week following dosing, along with a recovery of fat concentration thereafter. It should be noted that the data were confounded somewhat by the fact that nearly stable production of milk fat in the dosed cows immediately following dosing occurred over the same period during which some of the control cows experienced a transient trend toward increased in fat yield or concentration. However, none of the treatment or cow combinations fell below threshold of $32 \mathrm{~g}$ of fat/ $\mathrm{kg}$ of milk commonly used to define MFD in Holstein cows (Oetzel, 2007).

After dosing, VFA profiles in ruminal samples collected before feeding shifted slightly in the direction of butyrate from acetate (Table 3) with a resultant decrease in acetate-to-propionate ratio, but control cows also displayed similar shifts in VFA profiles following dosing with sterile medium. Dosing had no effect on ruminal $\mathrm{pH}$ or total millimolar VFA within either cow group. No dose-by-period interactions were seen for any of the ruminal chemistry variables tested, except for a tendency for an effect on molar fraction of butyrate. Of 72 ruminal samples collected before feeding (6 cows $\times 12$ sampling dates), lactate was only detected in a single sample, and in that case was present at low concentration $(3.6 \mathrm{mM})$.

Analysis of DNA isolated from the liquid phase of ruminal contents using ARISA revealed that the $M$. elsdenii population size spiked upon dosing with $M$. elsdenii, but within $1 \mathrm{~d}$ returned to undetectable levels in 2 of the 3 dosed cows (including cow 4079), and fluctuated near the minimal detectable limit in the third dosed cow (data not shown). In addition, 2 of the 3 control cows dosed only with lactate-free medium showed a weak signal for $M$. elsdenii on the very last sampling day (d 28) but not in any of the earlier samples. Taken together, the data suggested that $M$. elsdenii populations in the rumens of these cows were very low, and the dosed strain did not significantly persist in the rumens of the dosed cows. The general lack of persistence was accompanied by an overall lack of change in milk fat percentage or yield.

\section{Experiment 2}

The laboratory strain used in experiment 1 did not establish itself following ruminal dosing. To improve the success of dosing, a second experiment was conducted using freshly isolated strains of $M$. elsdenii isolated from cows in the same herd used for the dosing experiments. Two of the strains (4251 and 4257) were isolated from cows that displayed MFD at the time of sample collection for the original enrichment cultures, whereas the third isolate (4296) was from a cow whose fat test was marginal $(33 \mathrm{~g} / \mathrm{kg})$ at the time of ruminal sampling. To enhance the opportunity for successful establishment of the dosed strains, a multiple-dosing regimen was employed. The 3 strains were each dosed just before feeding on 4 separate days over a 5 -d period into 3 cows; none of these 9 cows displayed MFD $7 \mathrm{~d}$ before dosing. For each strain, 1 of the 3 recipient cows was the same cow from which the strain had originally been isolated (Figure 1). To enhance the detection for M. elsdenii, a more sensitive qPCR method was employed using M. elsdenii-specific primers.

Milk yield, fat yield, and percent milk fat did not change with dosing of any of the strains, though fat yield tended to be higher for the control cows across periods (Table 4). Within each dosing group, milk production was also compared across 3 periods: the days before dosing (pre-dose); the 5 -d period over which dosing occurred (hereafter referred to as the dosing week); and the days following the final dosing (postdose). As shown in Table 4, relative to the week before dosing, no significant changes in milk production, fat production, or fat concentration occurred during the 5 -d dosing period or in the 2 wk thereafter, although in 2 of the dose groups (M. elsdenii 4251 and control) slight changes in DMI occurred across these periods. Similarly, no significant differences in concentrations of protein or lactose were observed between predose, dose week, or postdose periods (data not shown). Significant $(P<$ 0.01 ) strain by period interactions were noted for DMI, milk yield, and fat yield. Examination of milk and fat production across periods for individual cows (Figure 3) revealed that only 2 of the 9 cows dosed with $M$. elsdenii showed a tendency toward decreased milk fat content (cow 4288) or fat yield (cow 4297) during the 
WEIMER ET AL.

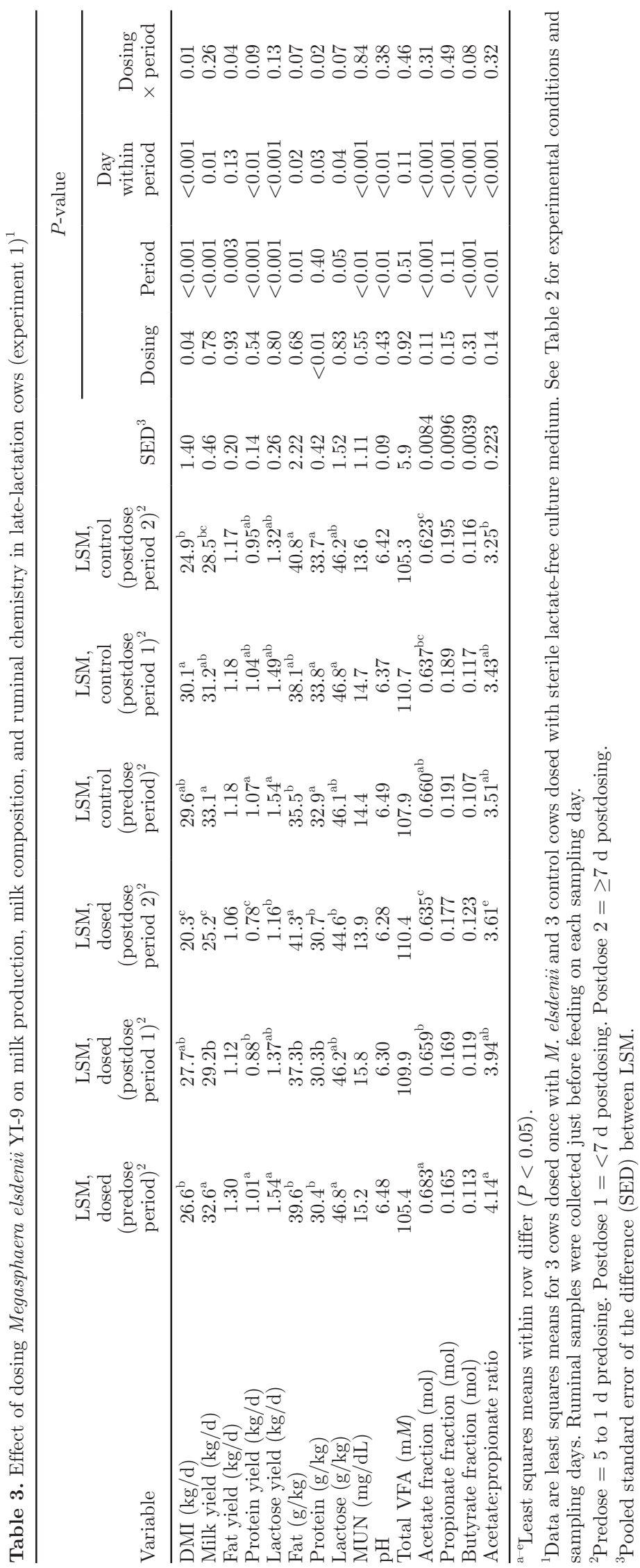


A)

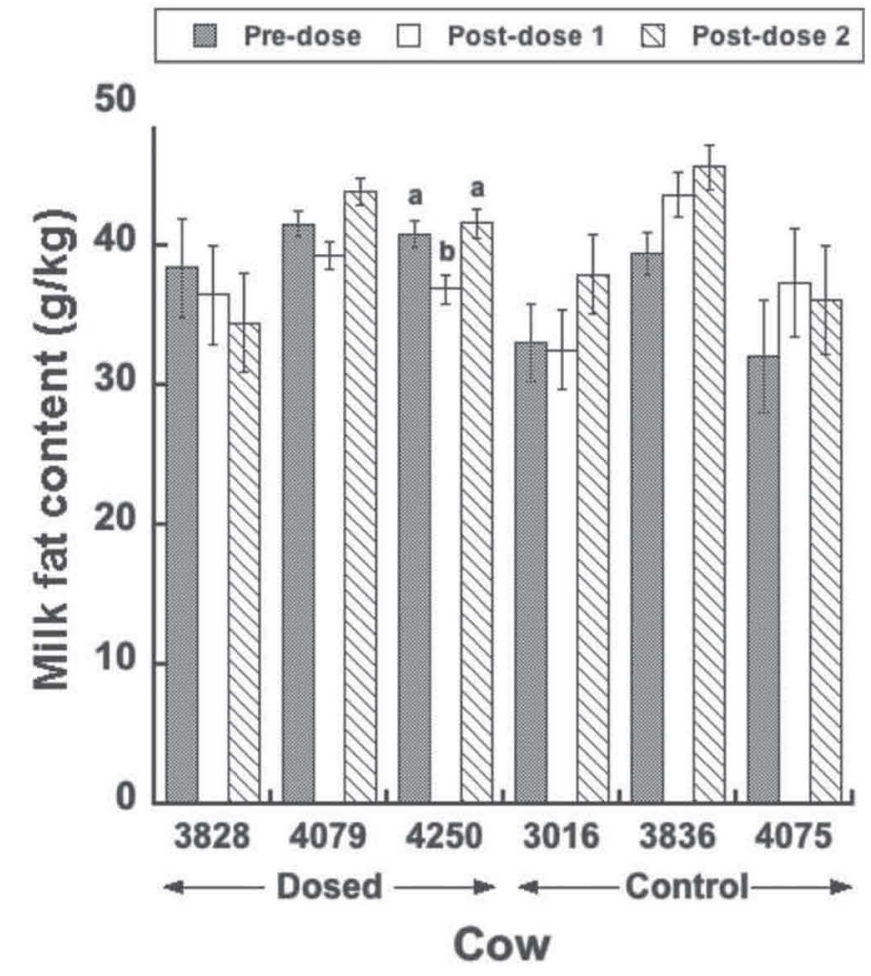

B)

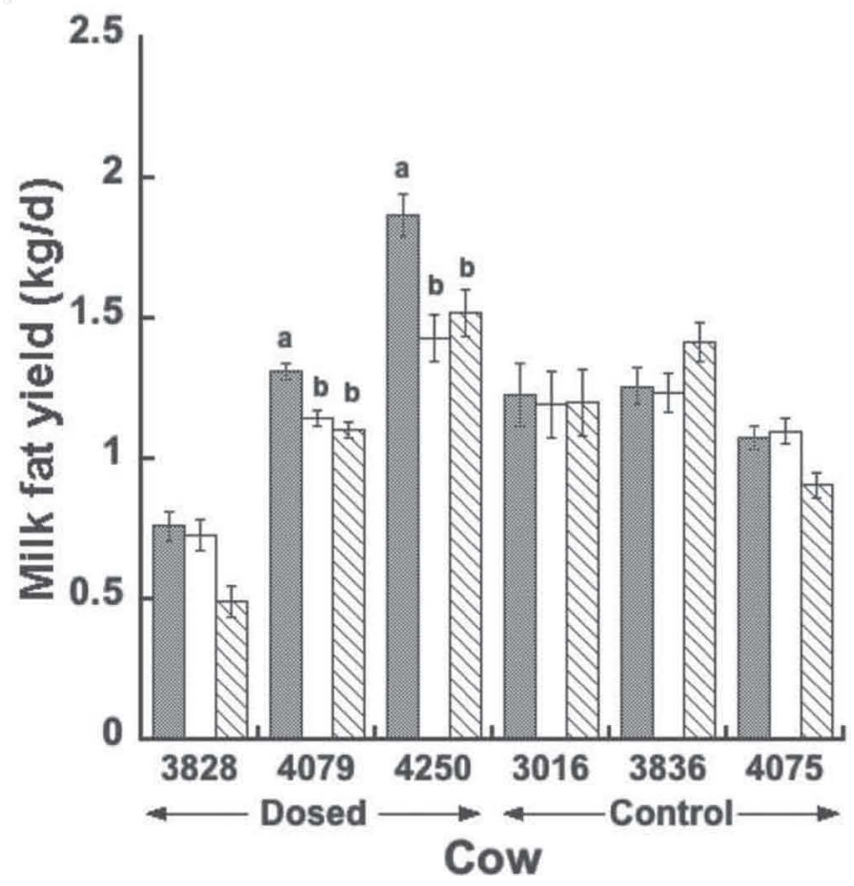

Figure 2. Milk fat content and milk fat yield in individual cows in experiment 1. Cows were dosed once with Megasphaera elsdenii YI-9 (dosed) or with an equal volume of sterile lactate-free medium (control). Data are least squares means from $2 \times$-daily milking for 3 periods: predose ( $\mathrm{d}-5$ to 0 ), postdose 1 ( $\mathrm{d} 1$ to 9 after dosing), and postdoes 2 (d 24 to 30 after dosing). Error bars represent SEM. Within cow, means for periods having different letters $(\mathrm{a}, \mathrm{b})$ differed $(P<$ 0.05). See Table 2 for experimental details. dosing week. Six of the 9 cows showed changes in fat content or fat yield during the remaining weeks (dosing week vs. postweek), but these were split evenly between increases or decreases.

As shown in Table 5, some differences existed in ruminal chemistry across treatment groups (the 3 groups dosed with different strains and the control group that received sterile lactate-free medium). Cows dosed with the M. elsdenii strains had slightly lower molar proportions of acetate and acetate to propionate, and slightly higher molar proportions of propionate and butyrate and a lower acetate to propionate compared with the control cows $(P<0.05)$, but there were no significant differences among the $3 \mathrm{M}$. elsdenii-dosing groups for any of the ruminal chemistry variables. For each of the 3 groups dosed with an $M$. elsdenii strain, but not the control group, transient increases in molar proportion of propionate and butyrate were observed, along with decreases in molar proportion of acetate and acetate to propionate during the dosing week, but these differences disappeared in the following weeks. These differences were not likely due to carryover effects from the dosed medium, as the ruminal fluid was collected just before feeding and dosing, and $\sim 24$ to $48 \mathrm{~h}$ after the previous dosing. Lactate was detected in a large percentage of ruminal samples (collected prefeeding) from all dose groups (the $3 \mathrm{M}$. elsdenii strains and the lactate-free medium: 15/33 predose, 20/44 dosing week, $34 / 55$ postdose) at concentrations up to $15 \mathrm{mM}$. Unexpectedly, lactate concentrations (though generally low) tended to be higher in the groups dosed with $M$. elsdenii than in the control cows (Table 6).

For each of the 9 cows dosed with $M$. elsdenii, the RPS of this species displayed spikes following each of the 4 dosings, to values of $\sim 0.1$ to $0.4 \%$ of $16 \mathrm{~S}$ rRNA gene copy number (Figure 4). However, the RPS returned to baseline values $(<0.01 \%)$ at the next sampling point 24 $\mathrm{h}$ later. The 2 control cows, each of which was subjected to 4 dosings with sterile medium without lactate, displayed very low RPS values $(<0.01 \%)$ at all sampling points before and after dosing. The RPS values were very low in all cow groups in the weeks following the dosing week.

\section{Experiment 3}

The lack of establishment of the freshly isolated strains in experiment 2 suggested that establishment conditions were suboptimal. This was perhaps due to the timing of the dose (just before feeding) or to the use of late-lactation cows whose overall production had declined at the end of the lactation cycle, and thus may have been relatively insensitive to physiological changes including milk fat production. A third experiment was 
conducted in which one of the strains used in experiment 2 ( $M$. elsdenii 4251, isolated from an MFD cow) was dosed into 4 early-lactation cows, including the cow from which the strain had been isolated and which had been dosed with this strain without apparent effect in experiment 2. As in the 2 previous experiments, none of the recipient cows displayed MFD when tested $5 \mathrm{~d}$ before dosing. Dosing was performed $4 \mathrm{~h}$ postfeeding to maximize the exposure of the fresh inoculum to lactate (expected to be more ruminally abundant a few hours after feeding). Because the rumens were very full $4 \mathrm{~h}$ after feeding, $\sim 8 \mathrm{~L}$ of ruminal contents $(\sim 10 \%$ of ruminal volume) was removed from each recipient before dosing to facilitate inoculum addition and hand-mixing of ruminal contents and to decrease the chance that the fresh inoculum would be rapidly passed from the rumen toward the omasum. Four other cows were dosed with sterile lactate-free medium, but one of these cows was subsequently removed from the trial due to development of mastitis the day after dosing.

Milk production data (Table 6) generally revealed no differences in yields of milk or milk components, or in percentages of components, between dosed and control cows or between periods (predose and postdose) in these midlactation cows. The sole exceptions were lower MUN and a tendency toward lower protein content in the postdosing period for both dosed and control cows. Comparison of milk and fat production data in individual cows revealed that both treatment groups (M. elsdenii and control) displayed slight numerical (but not statistically significant) declines in both milk fat and milk yield (Figure 5), and only one of the treatment and cow combinations fell below threshold of 32 $\mathrm{g}$ of fat $/ \mathrm{kg}$ of milk commonly used to define MFD in Holstein cows (Oetzel, 2007).

Total ruminal VFA did not differ between the 2 dosing groups either before or after dosing (Table 6) Cows dosed with $M$. elsdenii 4251 tended to display an increased molar proportion of propionate and numerically decreased molar proportion of acetate, resulting in a tendency to a decreased acetate-to-propionate ratio following dosing; this effect was not observed in control cows dosed with sterile lactate-free medium. Lactate was detected in 7 of 18 predose ruminal samples and 20 of 54 postdose samples (all collected just $4 \mathrm{~h}$ postfeeding), but concentrations typically were $<1 \mathrm{~m} M$ and never exceeded $7.1 \mathrm{~m} M$ in any sample.

The relative population size of $M$. elsdenii during experiment 3 is shown in Figure 6 . In 3 of the 4 cows dosed with $M$. elsdenii 4251, the RPS of $M$. elsdenii was very low $(<0.03 \%)$ before dosing, spiked briefly at dosing, and rapidly decreased to baseline levels within $24 \mathrm{~h}$ of dosing, suggesting that the dosed strain persisted poorly in the rumens of these cows. By contrast, the fourth cow (4251, from which the dosed strain $M$. elsdenii 4251 had originally been isolated) displayed a greater abundance that declined before dosing, spiked at dosing, and decreased substantially by the following day but then increased until $\mathrm{d} 7$, the final time point examined.

Table 4. Production summary for late-lactation cows dosed with different strains of Megasphaera elsdenii (experiment 2$)^{1}$

\begin{tabular}{|c|c|c|c|c|c|c|c|c|}
\hline \multirow[b]{2}{*}{ Variable } & \multirow[b]{2}{*}{ Dose group } & \multirow[b]{2}{*}{$\begin{array}{c}\text { LSM } \\
\text { Predose } \\
\text { period }\end{array}$} & \multirow[b]{2}{*}{$\begin{array}{c}\text { LSM } \\
\text { Dose } \\
\text { week }^{2}\end{array}$} & \multirow[b]{2}{*}{$\begin{array}{c}\text { LSM } \\
\text { Postdose } \\
\text { period }\end{array}$} & \multirow[b]{2}{*}{$\begin{array}{c}\text { Pooled } \\
\mathrm{SED}^{3}\end{array}$} & \multicolumn{3}{|c|}{$P$-value } \\
\hline & & & & & & Dose & Period & $\begin{array}{c}\text { Dose } \\
\times \text { period }\end{array}$ \\
\hline \multirow[t]{4}{*}{ DMI (kg/d) } & M. elsdenii 4251 & $22.5^{\mathrm{b}}$ & $24.6^{\mathrm{a}}$ & $23.7^{\mathrm{ab}}$ & \multirow[t]{4}{*}{0.42} & \multirow[t]{4}{*}{$<0.01$} & \multirow[t]{4}{*}{$<0.001$} & \multirow[t]{4}{*}{$<0.01$} \\
\hline & M. elsdenii 4257 & 23.6 & 24.1 & 23.3 & & & & \\
\hline & M. elsdenii 4296 & 27.3 & 28.5 & 28.6 & & & & \\
\hline & Control & $28.4^{\mathrm{a}}$ & $28.6^{\mathrm{a}}$ & $26.6^{\mathrm{b}}$ & & & & \\
\hline \multirow[t]{4}{*}{$\operatorname{Milk}(\mathrm{kg} / \mathrm{d})$} & M. elsdenii 4251 & 30.4 & 31.6 & 33.6 & \multirow[t]{4}{*}{0.93} & \multirow[t]{4}{*}{0.31} & \multirow[t]{4}{*}{0.29} & \multirow[t]{4}{*}{$<0.001$} \\
\hline & M. elsdenii 4257 & 26.4 & 26.0 & 26.0 & & & & \\
\hline & M. elsdenii 4296 & 38.3 & 35.6 & 37.2 & & & & \\
\hline & Control & 41.4 & 40.6 & 39.0 & & & & \\
\hline \multirow[t]{4}{*}{ Milk fat $(\mathrm{kg} / \mathrm{d})$} & M. elsdenii 4251 & 1.12 & 1.20 & 1.28 & \multirow[t]{4}{*}{0.07} & \multirow[t]{4}{*}{0.095} & \multirow[t]{4}{*}{0.40} & \multirow[t]{4}{*}{0.03} \\
\hline & M. elsdenii 4257 & 1.08 & 1.12 & 0.99 & & & & \\
\hline & M. elsdenii 4296 & 1.30 & 1.26 & 1.29 & & & & \\
\hline & Control & 1.59 & 1.63 & 1.45 & & & & \\
\hline \multirow[t]{4}{*}{ Milk fat (g/kg) } & M. elsdenii 4251 & 39.8 & 38.3 & 39.6 & \multirow[t]{4}{*}{2.6} & \multirow[t]{4}{*}{0.30} & \multirow[t]{4}{*}{0.74} & \multirow[t]{4}{*}{0.02} \\
\hline & M. elsdenii 4257 & 41.1 & 39.9 & 38.9 & & & & \\
\hline & M. elsdenii 4296 & 35.6 & 35.5 & 35.7 & & & & \\
\hline & Control & 40.9 & 40.0 & 40.2 & & & & \\
\hline
\end{tabular}

\footnotetext{
${ }^{\mathrm{a}, \mathrm{b}}$ Least squares means within row differ $(P<0.05) .{ }^{1}$ Data are LSM for 3 cows in each dose group, or for 2 cows in the control group dosed with sterile lactate-free culture medium. See Figure 1 for dosing schematic and Table 2 for experimental conditions and sampling days.

${ }^{2}$ Dose week $=$ milk samples collected in the $5 \mathrm{~d}$ following the first of 4 dosings.

${ }^{3}$ Pooled standard error of the difference (SED) between LSM.
} 

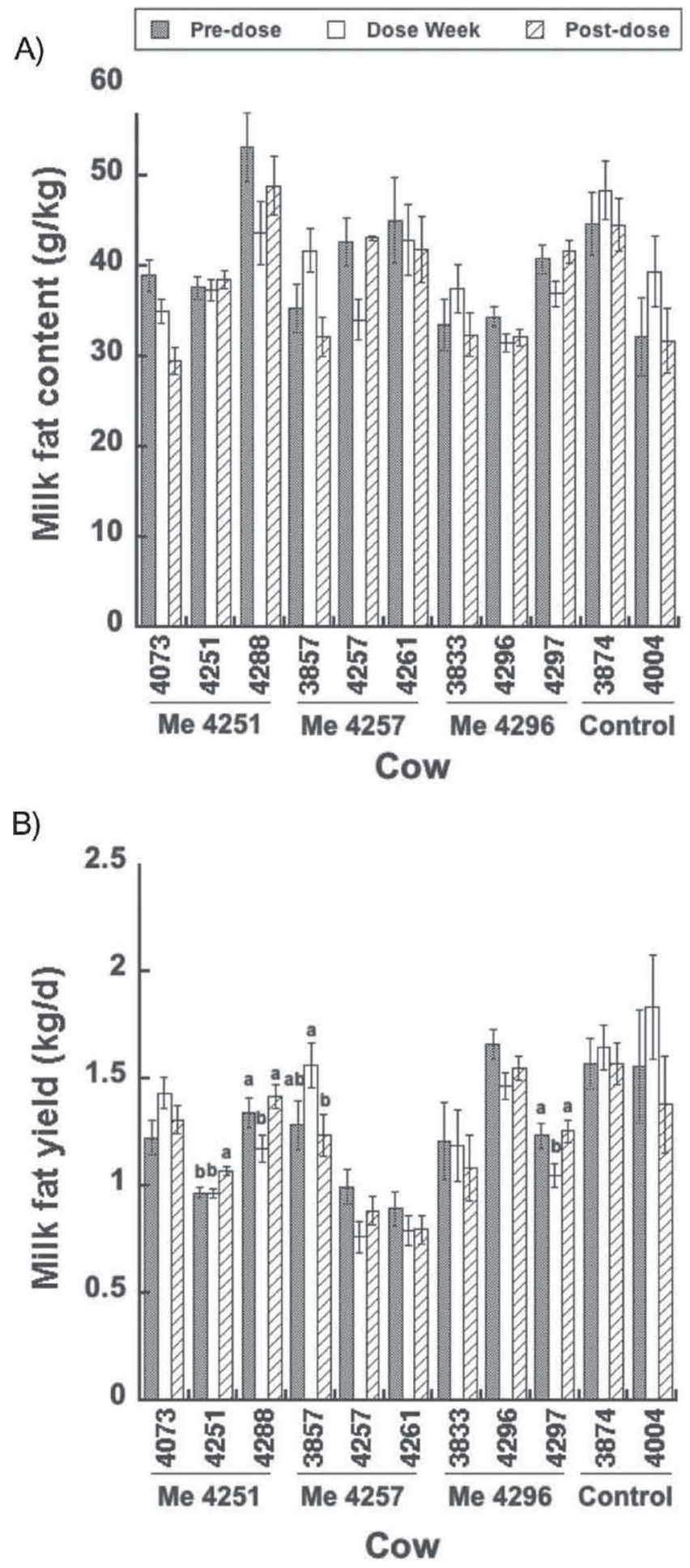

Figure 3. Milk fat content and milk fat yield in individual cows in experiment 2. Cows were dosed 4 times over a 5 -d period with the indicated strain of Megasphaera elsdenii, or with an equal volume of sterile lactate-free medium (control). Data are LSM from $3 \times$-daily milking for 3 periods: predose ( $\mathrm{d}-5$ to 0 ), dose week (d 1 to 5 after the first dosing), and postdose (d 7, 9, 11, 14, 18, and 21 after the first dosing). Error bars represent SEM. Within cow, means for periods having different letters $(\mathrm{a}, \mathrm{b})$ differed $(P<0.05)$. See Table 2 for experimental details.

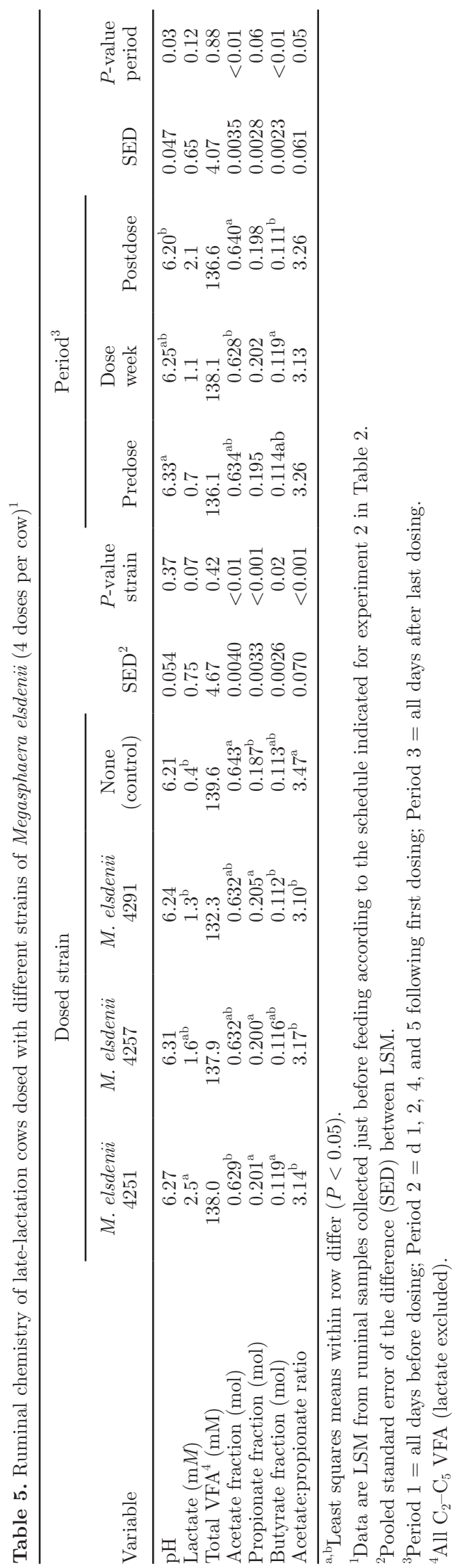

Journal of Dairy Science Vol. 98 No. 11, 2015 
Table 6. Effect of dosing early-lactation cows with Megasphaera elsdenii 4251 on milk production, milk composition, and ruminal chemistry (experiment 3$)^{1}$

\begin{tabular}{|c|c|c|c|c|c|c|c|c|c|}
\hline Variable & $\begin{array}{c}\text { LSM, } \\
\text { dosed } \\
\text { (predose } \\
\text { period) }\end{array}$ & $\begin{array}{c}\text { LSM, } \\
\text { dosed } \\
\text { (postdose } \\
\text { period) }\end{array}$ & $\begin{array}{c}\text { LSM, } \\
\text { control } \\
\text { (predose } \\
\text { period) }\end{array}$ & $\begin{array}{c}\text { LSM, } \\
\text { control } \\
\text { (postdose } \\
\text { period) }\end{array}$ & $\mathrm{SED}^{2}$ & \multicolumn{4}{|c|}{$P$-value } \\
\hline \multicolumn{10}{|l|}{ Milk } \\
\hline DMI (kg/d) & 28.0 & 26.4 & 31.6 & 30.9 & 2.51 & 0.30 & $<0.01$ & $<0.001$ & 0.17 \\
\hline Milk yield $(\mathrm{kg} / \mathrm{d})$ & 50.1 & 50.8 & 50.7 & 52.2 & 4.21 & 0.87 & 0.19 & 0.25 & 0.61 \\
\hline Fat yield $(\mathrm{kg} / \mathrm{d})$ & 1.84 & 1.76 & 1.99 & 1.92 & 1.54 & 0.44 & 0.26 & 0.03 & 0.97 \\
\hline Milk protein ( $\mathrm{g} / \mathrm{kg}$ of milk) & 26.3 & 26.6 & 27.0 & 26.9 & 1.13 & 0.78 & 0.64 & $<0.001$ & 0.24 \\
\hline MUN (mg/dL of milk) & 11.7 & 10.9 & 12.1 & 11.4 & 0.60 & 0.53 & 0.03 & $<0.001$ & 1.00 \\
\hline \multicolumn{10}{|l|}{ Ruminal chemistry } \\
\hline $\mathrm{pH}$ & $6.09^{\mathrm{ab}}$ & $5.70^{\mathrm{b}}$ & $6.20^{\mathrm{a}}$ & $6.05^{\mathrm{ab}}$ & 0.083 & 0.03 & $<0.01$ & $<0.01$ & 0.05 \\
\hline Lactate $(\mathrm{m} M)$ & 0.36 & 0.80 & 1.07 & 0.81 & 0.28 & 0.08 & 0.78 & 0.82 & 0.05 \\
\hline Total $\mathrm{VFA}^{3}(\mathrm{~m} M)$ & 142.1 & 152.6 & 153.6 & 145.7 & 11.9 & 0.88 & 0.73 & 0.04 & 0.05 \\
\hline Acetate fraction $(\mathrm{mol})$ & $0.628^{\mathrm{ab}}$ & $0.610^{\mathrm{b}}$ & $0.642^{\mathrm{a}}$ & $0.644^{\mathrm{a}}$ & 0.0082 & 0.06 & 0.09 & $<0.001$ & 0.08 \\
\hline
\end{tabular}

${ }^{\mathrm{a}, \mathrm{b}}$ Least squares means within row differ $(P<0.05)$.

${ }^{1}$ See Table 2 for experimental conditions and sampling days.

${ }^{2}$ Pooled standard error of the difference (SED) between LSM.

${ }^{3} \mathrm{All} \mathrm{C}_{2}-\mathrm{C}_{5}$ VFA (lactate excluded).

${ }^{4}$ Relative population size of $M$. elsdenii, as percentage of total bacterial 16S rRNA gene copy number.

\section{DISCUSSION}

Megasphaera elsdenii has consistently been shown to have an elevated abundance in MFD cows using both culture-based methods (Latham et al., 1972) and culture-independent molecular methods (Palmonari et al., 2010; Weimer et al., 2010b; Mohammed et al., 2012); in several of these studies individual cows have demonstrated substantial reductions in relative abundance of this bacterium upon recovery from MFD. However, such studies are limited by their purely associative nature. Demonstrating a cause-and-effect relationship between a suspected agent and MFD is experimentally challenging, as cows must be on a diet containing the ingredients known to increase the risk of MFD (e.g., certain long-chain FA) without actually eliciting MFD in the absence of dosing (i.e., in undosed control cows). The challenge is further magnified by the considerable variation among individual cows with respect to their susceptibility to MFD on a given diet (Palmonari et al., 2010; Weimer et al., 2010b; Mohammed et al., 2012).

In the present study, direct dosing of various strains of $M$. elsdenii into the rumen via the ruminal cannula resulted in transient RPS of this species of $\sim 0.2$ to $0.4 \%$ of $16 \mathrm{~S}$ rRNA gene copy number, determined about $1 \mathrm{~h}$ postdosing. These RPS values approximate those observed in some cases of MFD (Palmonari et al., 2010; Weimer et al., 2010b; Mohammed et al., 2012).
However, despite the large dose size $(\sim 3 \mathrm{~L}$ of culture containing $\sim 2 \times 10^{12}$ cells), with one exception, $M$. elsdenii levels returned to very low baseline levels (RPS $\sim 0.02 \%$ ) within $24 \mathrm{~h}$ of dosing. This lack of persistence was observed even when 4 dosings were conducted over a 5-d period (experiment 2). The return to baseline was also observed in the 3 cows in experiment 2 that were dosed with the strain originally isolated from that particular recipient cow (cows 4251, 4257, and 4296). The sole exception to the general lack of persistence was observed in experiment 3, in which cow 4251 (from which the strain had originally been isolated) originally lost much of the dosed strain, but then rebounded to reach an M. elsdenii RPS of $\sim 0.19 \%$ by $7 \mathrm{~d}$ postdosing, the last time point of the experiment; this RPS was about half that observed upon initial dosing, and much higher than the RPS in the same cow immediately before dosing. Partial success may have resulted from the timing of the dosing $(\sim 4 \mathrm{~h}$ postfeed, when more lactate was likely to be produced from the rapidly digestible starch in the TMR), removal of a small fraction of ruminal contents at the time of dosing (to facilitate inoculation into a full rumen and to reduce immediate passage of dosed material out of the rumen), and dosing earlier in the lactation cycle (during which the cow may be more sensitive to metabolic changes that contribute to MFD). The varying response of individual animals to the dosing, specifically the establishment of strain 4251 
Dosed with $M$. elsdenii 4251

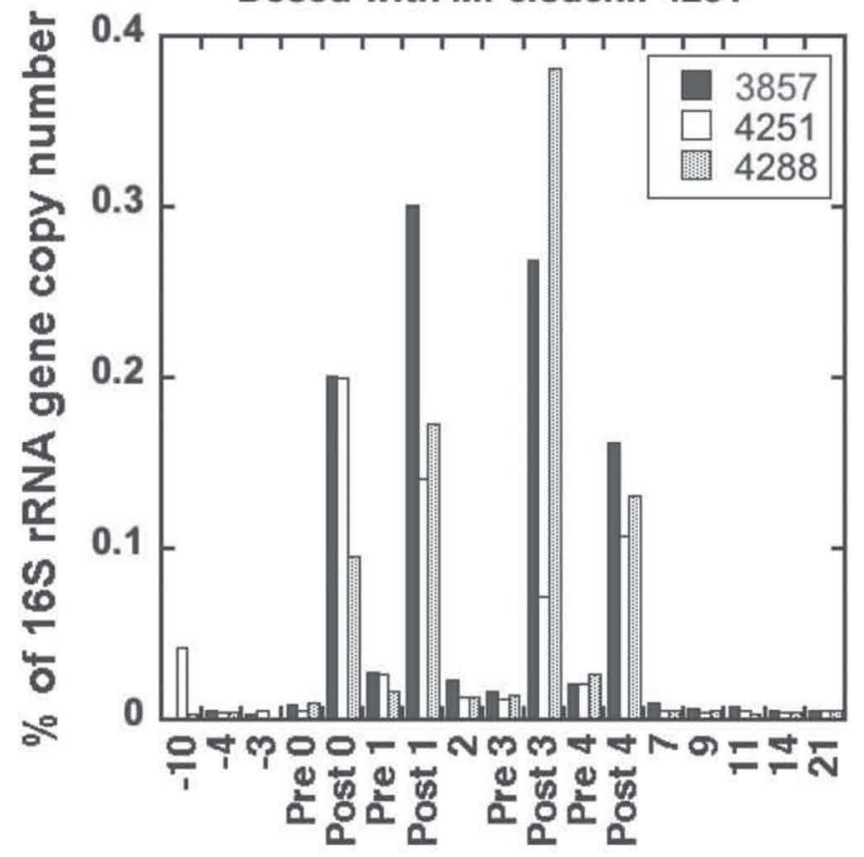

Day

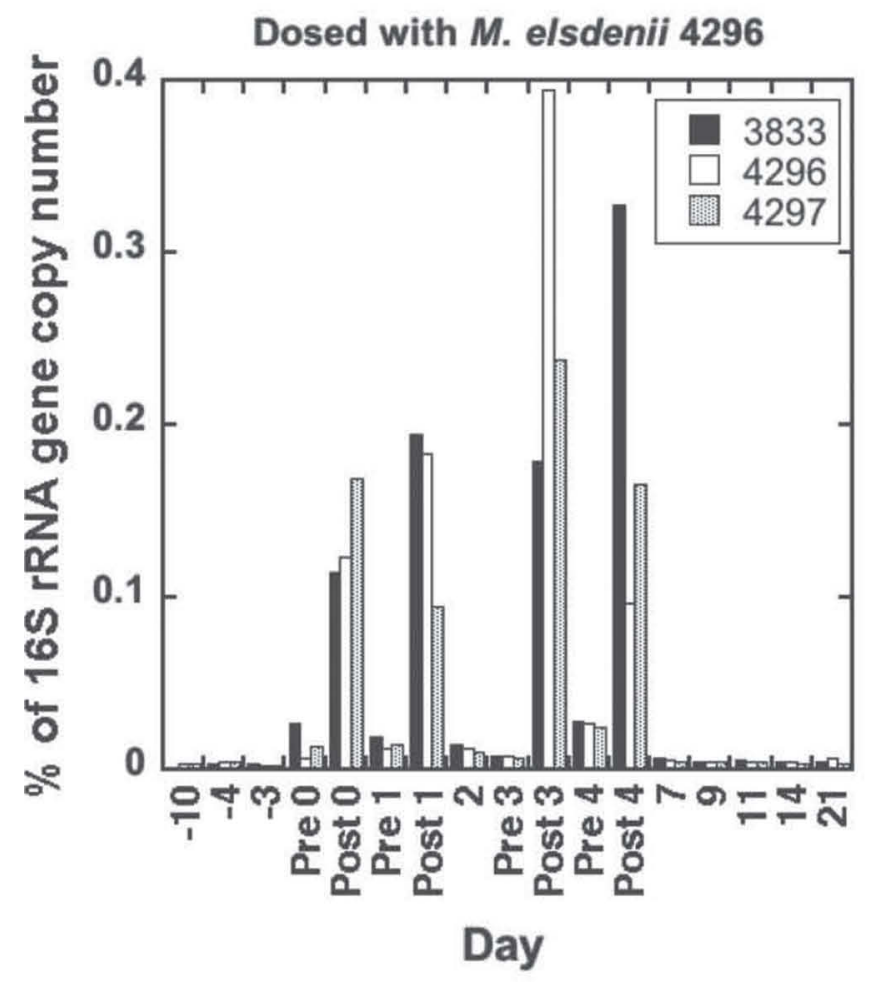

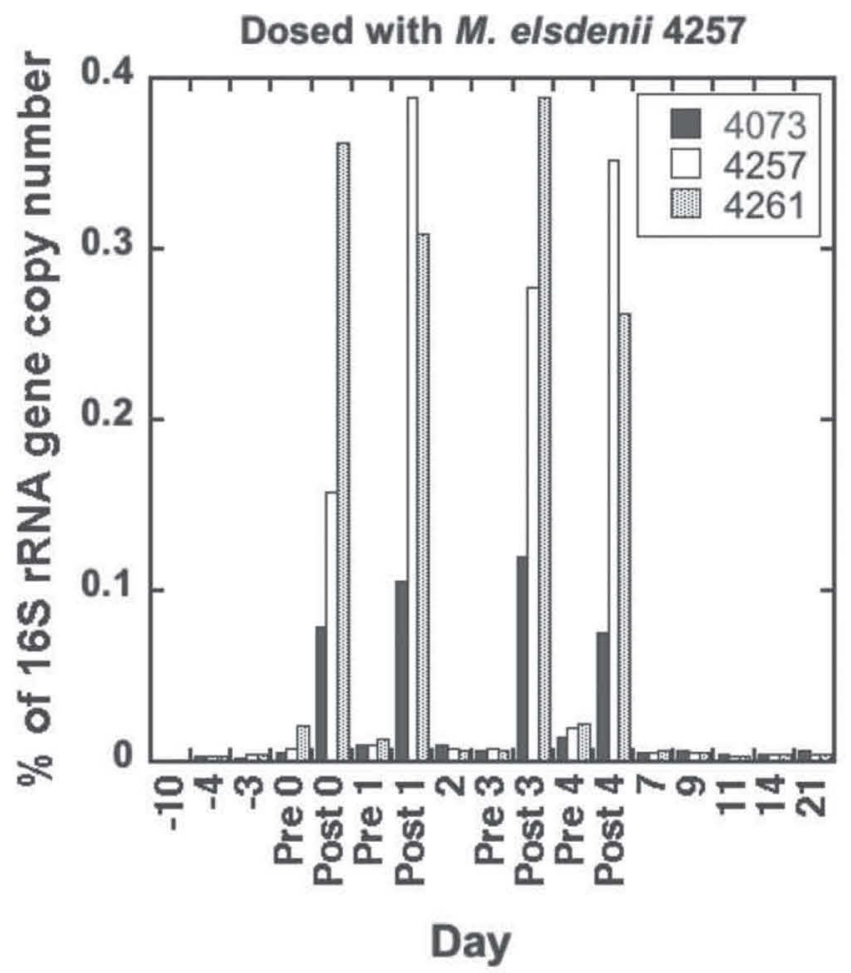

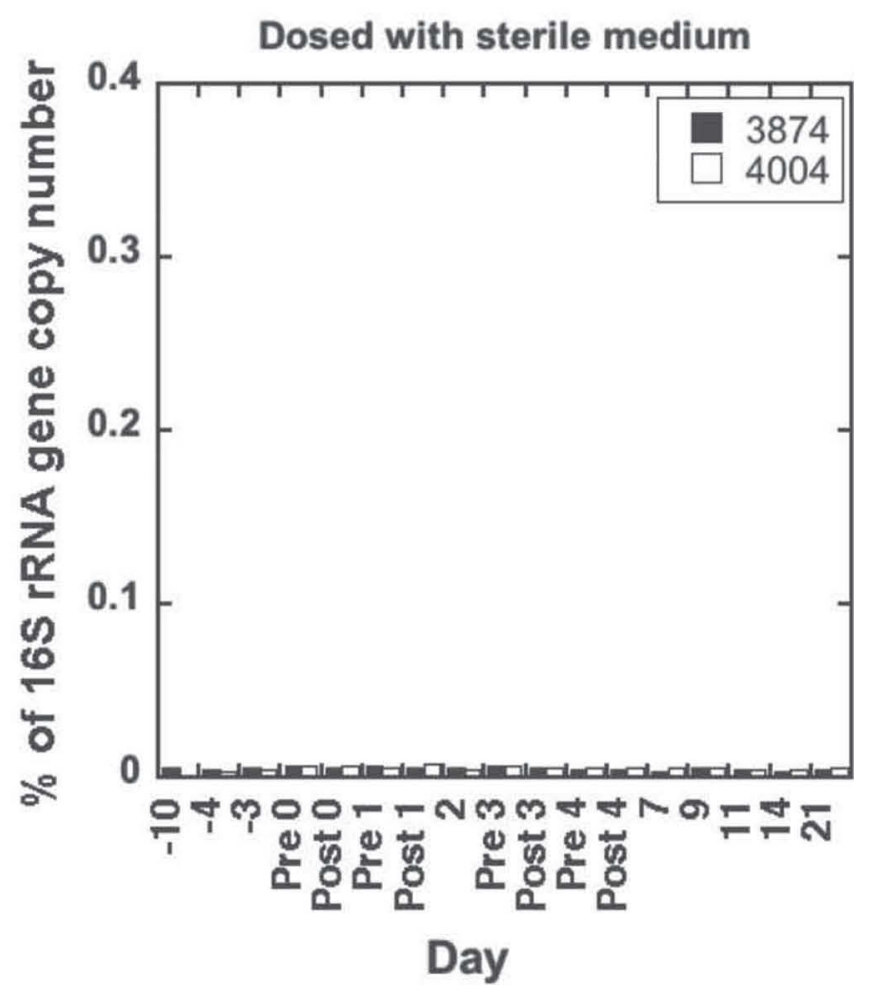

Figure 4. Relative population size of Megasphaera elsdenii before and after dosing of late-lactation cows (experiment 2). Dosing was conducted just before feeding, and all samples were collected just before feeding on the individual day, except for the postdosing samples that were collected $\sim 1 \mathrm{~h}$ after dosing. Each panel represents dosing of 3 cows with an individual $M$. elsdenii strain or a dosing of 2 control cows with sterile lactate-free medium. 

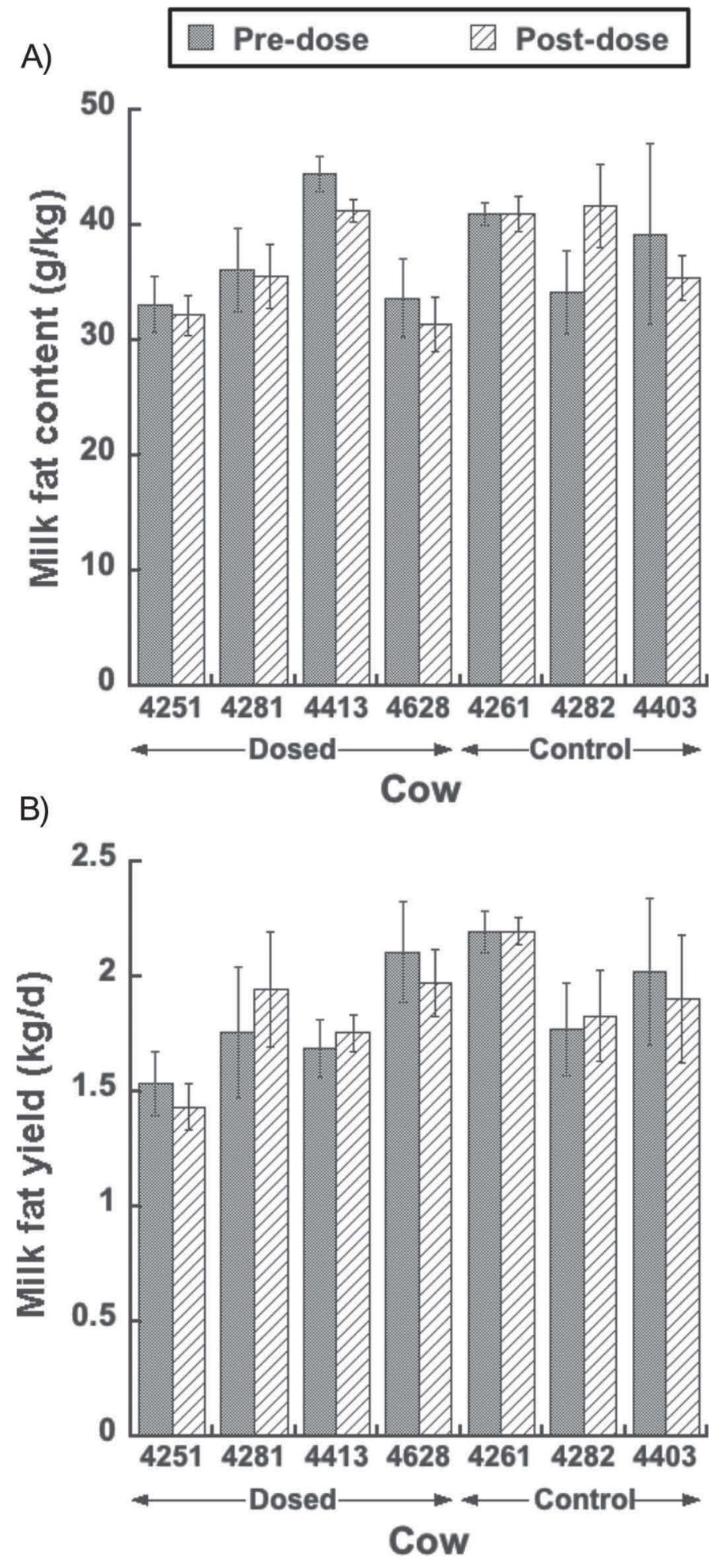

Figure 5. Milk fat content and milk fat yield in individual cows in experiment 3. Cows were dosed once with Megasphaera elsdenii 4251 (dosed) or with an equal volume of sterile lactate-free medium (control). Data are LSM from $3 \times$-daily milking for 2 periods: predosing $(\mathrm{d}$ -5 to 0 ), and postdose (d 1 to 7 after dosing). Error bars represent SEM. See Table 2 for experimental details.
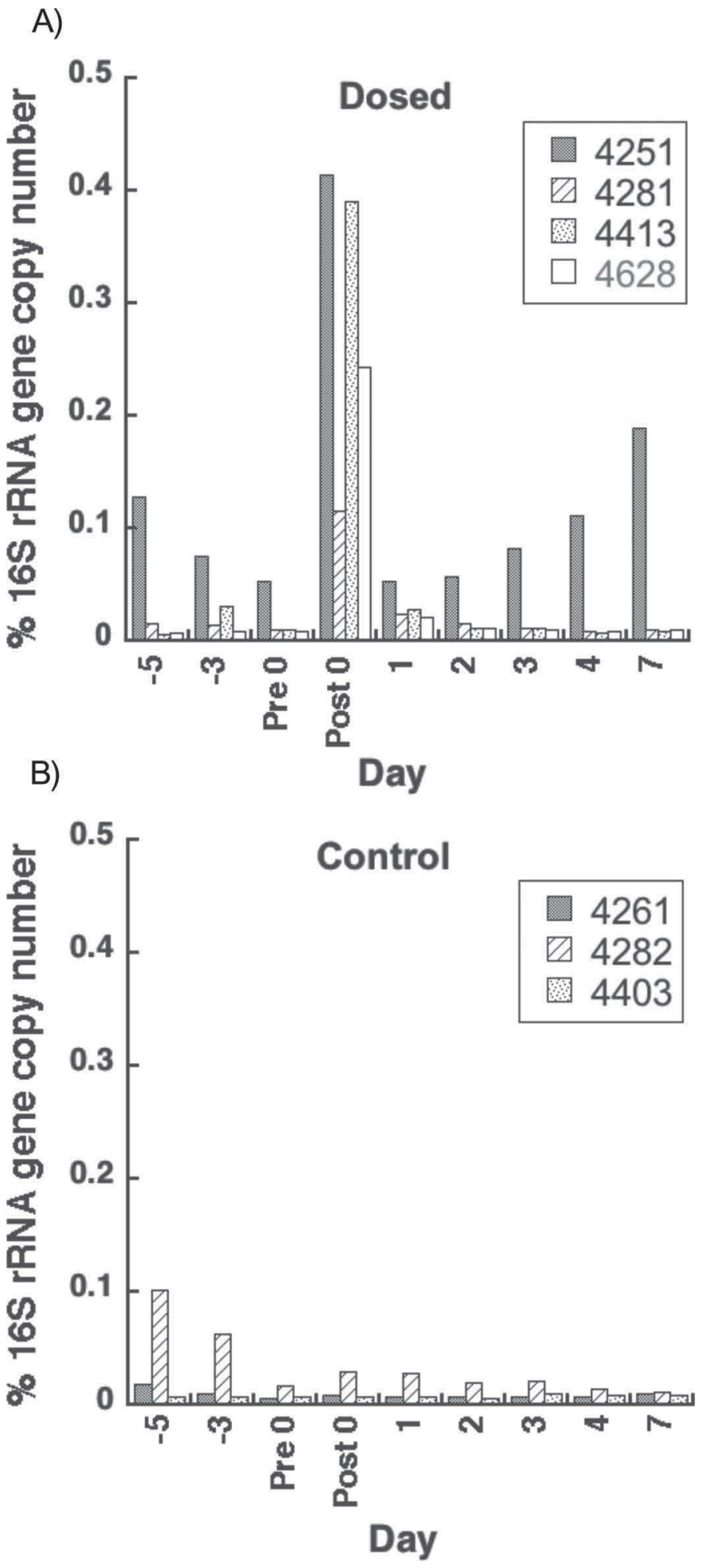

Figure 6. Relative population size of Megasphaera elsdenii before and after dosing early-lactation cows with M. elsdenii strain 4251 (experiment 3). Dosing was conducted $4 \mathrm{~h}$ postfeeding, and all samples were collected at $4 \mathrm{~h}$ postfeeding on the individual day, except for the first postdosing sample that was collected $\sim 1 \mathrm{~h}$ after dosing. Control cows were dosed with sterile lactate-free medium. 
in its original source cow, is in accord with previous demonstrations that the ruminal microbiome displays substantial host specificity (Weimer et al., 2010a). However, it must be pointed out that, in experiment 3, cow 4251 displayed atypically high (though decreasing) RPS of M. elsdenii in the few days before dosing, and the possibility exists that at least some of the increased RPS that followed dosing could be due to natural fluctuations in the abundance of this species in that particular rumen, independent of dosing, or resulting from the previous dosing experiment (experiment 2, conducted 5 mo earlier), after which it had appeared to have been rapidly cleared. Regardless, the observed RPS was not associated with a significant decrease in milk fat yield or concentration, perhaps due to the short time course of this particular experiment.

Megasphaera elsdenii has been the subject of several dosing studies aimed at testing its ability to protect cows from lactic acidosis when fed high-concentrate diets. Meissner et al. (2010), in an exhaustive review on the potential for $M$. elsdenii to serve as a probiotic for this purpose, noted that most strains tested, including several patented strains, are ineffective in vivo due to "one or more reasons which include inadequate growth rate, inability to multiply at a low ruminal $\mathrm{pH}$, nonpreferential use of lactate as primary substrate, inability to survive in suboptimal anaerobic conditions, inhibition by ionophores, inadequate delivery methods to the ruminant and inability to keep on producing acetate when fiber digesters become inhibited." Meissner et al. (2010) further noted that 1 M. elsdenii strain, NCIMB 41125, has shown efficacy in modulating ruminal $\mathrm{pH}$ under some conditions. In general, these studies focused on $\mathrm{pH}$ dynamics and sometimes reported production responses (milk production and composition and ruminal chemistry) that varied across studies. For example, dosing with strain NCIMB 41125 at 2 and $10 \mathrm{~d}$ postpartum resulted in nonsignificant $(P=0.19)$ decrease in milk fat content over $14 \mathrm{wk}$ in a group of 80 cows, but a trend $(P=0.08)$ toward decreased fat in a subset of 32 high-producing cows and significant $(P=0.005)$ fat reduction in a subset of 16 cows used for analysis of ruminal chemistry. Unfortunately the abundance of M. elsdenii in ruminal contents in those studies was not measured.

The study of Klieve et al. (2003) is of particular interest because it focused on strain persistence. Those authors reported that ruminal dosing of steers with a combination of M. elsdenii strain YE34 and Butyrvibrio fibrisolvens strain YE44 during a switch to a high-grain diet resulted in the establishment of the former species, but not the latter, and establishment at the observed population densities ( $\sim 10^{8}$ cells $/ \mathrm{mL}$ of ruminal liquid) occurred $\sim 4 \mathrm{~d}$ earlier than the eventual establishment of this species at similar population levels in control cows dosed with a placebo. Those isolates were obtained from an earlier study with different cattle that had been adapted to a high-grain diet. Successful establishment of the dosed strain was likely due to a combination of the strain's source (the rumen of a concentrate-adapted steer) and timing of the inoculation (to coincide with a shift to a high-grain diet that stimulates lactate producing bacteria). Our data support this notion that successful establishment of an inoculated M. elsdenii is highly dependent on a combination of factors, including strain, recipient animal, and timing of dosing in terms of both the feeding cycle and the lactation cycle.

The primary question that motivated our study, whether or not $M$. elsdenii is a causative agent of MFD, currently remains unanswered, primarily due to the substantial difficulty in establishing MFD upon dosing that is a necessary prerequisite for demonstrating cause and effect. Further studies, using early-lactation cows in concert with partial ruminal emptying during inoculation, and perhaps containing dietary components that poise cows closer to the edge of MFD, may provide a more definitive answer.

\section{ACKNOWLEDGMENTS}

We thank C. L. Odt for excellent technical assistance; D. M. Stevenson for advice on ARISA and qPCR; R. Skoyen, M. W. Hintz, K. Pickar, and the barn crew (all of the US Dairy Forage Research Center) for herd maintenance and animal handling; and M. B. Hall for stimulating discussions and statistical advice. This work was supported by the USDA-Agricultural Research Service through CRIS project 3655-21000-02400-D. L. Da Silva Cabral was supported by a fellowship from Conselho Nacional Desenvolvimento Cientifico e Technológica (CNPq), Brasilia, Brazil. F. Cacite was supported by the Brazilian Scientific Mobility Program, CNPq. The USDA is an Equal Opportunity Employer.

\section{REFERENCES}

Aikman, P. C., R. H. Henning, D. J. Humphries, and C. H. Horn. 2011. Rumen $\mathrm{pH}$ and fermentation characteristics in dairy cows supplemented with Megasphaera elsdenii NCIMB 41125 in early lactation. J. Dairy Sci. 94:2840-2849. http://dx.doi.org/10.3168/ jds.2010-3783.

Bauman, D. E., and J. M. Griinari. 2003. Nutritional regulation of milk fat synthesis. Annu. Rev. Nutr. 23:203-227. http://dx.doi. org/10.1146/annurev.nutr.23.011702.073408.

Hagg, F. M., L. J. Erasmus, P. H. Henning, and R. J. Coetze. 2010. The effect of a direct-fed microbial (Megasphaera elsdenii) on the productivity and health of Holstein cows. S. Afr. J. Anim. Sci. 40:101-112.

Henderson, G., C. Cox, S. Kittelmann, V. H. Miri, M. Zethof, S. J. Noel, G. C. Waghorn, and P. H. Janssen. 2013. Effect of DNA extraction methods and sampling techniques on the apparent struc- 
ture of cow and sheep rumen microbial communities. PLoS ONE 8:e74787 http://dx.doi.org/10.1371/journal.pone.0074787.

Henning, P. H., L. Erasmus, H. H. Meissner, and C. H. Horn. 2011. The effect of dosing Megaspheara elsdenii NCIMB 41125 ( Me) on lactation performance of multiparous Holstein cows. S. Afr. J. Anim. Sci. 41:156-160.

Hino, T., K. Shimada, and T. Maruyama. 1994. Substrate preference in a strain of Megasphaera elsdenii, a ruminal bacterium, and its implications in propionate production and growth competition. Appl. Environ. Microbiol. 60:1827-1831.

Horn, C. H., A. Kistner, B. J. Greyling, and A. H. Smith. Inventors. 2009. Megasphaera elsdenii and its uses. US Pat. No. 7,550,139 B2 Assignees: Agriculture Research Council, Pretoria, South Africa, and Yara Phosphates Oy, Helsinki, Finland.

Kim, Y. J., R. H. Liu, J. L. Rychlik, and J. B. Russell. 2002. The enrichment of a ruminal bacterium (Megasphaera elsdenii YJ-4) that produces the trans-10, cis-12 isomer of conjugated linoleic acid. J. Appl. Microbiol. 92:976-982.

Klieve, A. V., D. Hennessy, D. Ouwerkerk, R. J. Forster, R. I. Mackie, and G. T. Attwood. 2003. Establishing populations of Megasphaer elsdenii YE34 and Butyrvibrio fibrisolvens YE44 in the rumen of cattle fed high grain diets. J. Appl. Microbiol. 95:621-630. http:// dx.doi.org/10.1046/j.1365-2672.2003.02024.x.

Krause, K. M., and G. R. Oetzel. 2006. Understanding and preventing subacute ruminal acidosis in dairy herds: A review. Anim. Feed Sci. Technol. 126:215-236. http://dx.doi.org/10.1016/j. anifeedsci.2005.08.004

Latham, M. J., J. E. Storry, and M. E. Sharpe. 1972. Effect of lowroughage diets on the microflora and lipid metabolism in the rumen. Appl. Microbiol. 24:871-877.

Leedle, J. A. Z., R. C. Greening, and W. R. Smolenski. Inventors 1990. Ruminal bacterium for prevention of acute lactic acidosis. US Pat. No. 5,380,525. Assignee: The Upjohn Co., Kalamazoo, MI.

Maia, M. R. G., L. C. Chaudhary, L. Figueres, and R. J. Wallace. 2007. Metabolism of polyunsaturated fatty acids and their toxicity to the microflora of the rumen. Antonie van Leeuwenhoek 91:303-314.

Meissner, H. H., P. H. Henning, C. H. Horn, K. L. Leeuw, F. M. Hagg, and G. Fouche. 2010. Ruminal acidosis: A review with detailed reference to the controlling agent Megasphaera elsdenii NCIMB 41125. S. Afr. J. Anim. Sci. 40:79-100.

Mohammed, R., D. M. Stevenson, K. A. Beauchemin, R. E. Muck, and P. J. Weimer. 2012. Changes in ruminal bacterial community composition following feeding of alfalfa silage inoculated with a commercial silage inoculant. J. Dairy Sci. 95:328-339. http://dx.doi. org/10.3168/jds.2011-4492.
NRC. 2001. Nutrient Requirements of Dairy Cattle, 7th rev. ed., Natl. Acad. Press, Washington, DC.

Oetzel, G. 2007. Subacute ruminal acidosis in dairy herds: Physiology, pathophysiology, milk fat responses, and nutritional management. 40th Ann. Conf. Am. Assoc. Bovine Practitioners Preconference Seminar 7A: Dairy Herd Problem Investigation Strategies: Lameness, Cow Comfort, and Ruminal Acidosis, Vancouver, BC. Accessed Mar. 18, 2015. http://www.vetmed.wisc.edu/dms/fapm/ fapmtools/2nutr/sara1aabp.pdf.

Palmonari, A., D. M. Stevenson, D. R. Mertens, C. W. Cruywagen, and P. J. Weimer. 2010. pH dynamics and bacterial community composition in the rumen of lactating dairy cows. J. Dairy Sci. 93:279-287. http://dx.doi.org/10.3168/jds.2009-2207.

Petri, R. M., T. Schwaiger, G. B. Penner, K. A. Beauchemin, R. J. Forster, J. J. McKinnon, and T. A. McAllister. 2013. Changes in the rumen epimural bacterial diversity of beef cattle as affected by diet and induced ruminal acidosis. Appl. Environ. Microbiol. 79:3744-3755. http://dx.doi.org/10.1128/AEM.03983-12.

Russell, J. R., and T. Hino. 1985. Regulation of lactate production in Streptococcus bovis: A spiraling effect that contributes to rumen acidosis. J. Dairy Sci. 68:1712-1721.

Stevenson, D. M., and P. J. Weimer. 2007. Dominance of Prevotella and low abundance of classical ruminal bacterial species in the bovine rumen revealed by relative quantification real-time PCR. Appl Microbiol. Biotechnol. 75:165-174. http://dx.doi.org/10.1007/ s00253-006-0802-y.

Weimer, P. J. 1998. Manipulating ruminal fermentation: A microbial ecological perspective. J. Anim. Sci. 76:3114-3122.

Weimer, P. J., and G. N. Moen. 2013. Quantitative analysis of growth and volatile fatty acid production by the anaerobic ruminal bacterium Megasphaera elsdenii T81. Appl. Microbiol. Biotechnol. 97:4075-4081. http://dx.doi.org/10.1007/s00253-012-4645-4.

Weimer, P. J., Y. Shi, and C. L. Odt. 1991. A segmented gas/liquid delivery system for continuous culture of microorganisms on solid substrates, and its use for growth of Ruminococcus flavefaciens on cellulose. Appl. Microbiol. Biotechnol. 36:178-183.

Weimer, P. J., D. M. Stevenson, H. C. Mantovani, and S. L. C. Man. 2010a. Host specificity of the ruminal bacterial community of the dairy cow following near-total exchange of ruminal contents. J. Dairy Sci. 93:5902-5912. http://dx.doi.org/10.3168/jds.2010-3500.

Weimer, P. J., D. M. Stevenson, and D. R. Mertens. 2010b. Shifts in bacterial community composition in the rumen of lactating dairy cows under milk fat-depressing conditions. J. Dairy Sci. 93:265278. http://dx.doi.org/10.3168/jds.2009-2206. 